Article

\title{
Soil Quality Assessment Based on a Minimum Data Set: A Case Study of a County in the Typical River Delta Wetlands
}

\author{
Mingliang Jiang ${ }^{1,2} \mathbb{D}$, Ligang $X u^{1, * \mathbb{C}}$, Xiaobing Chen ${ }^{3, *}$, Hua Zhu ${ }^{1,2} \mathbb{D}$ and Hongxiang Fan ${ }^{1}$ \\ 1 Key Laboratory of Watershed Geographic Sciences, Nanjing Institute of Geography and Limnology, \\ Chinese Academy of Sciences, Nanjing 210008, China; jiangmingliang18@mails.ucas.ac.cn (M.J.); \\ zhuhua18@mails.ucas.ac.cn (H.Z.); hxfan@niglas.ac.cn (H.F.) \\ 2 College of Resources and Environment, University of Chinese Academy of Sciences, Beijing 100049, China \\ 3 Key Laboratory of Coastal Environmental Processes and Ecological Remediation, Yantai Institute of Coastal \\ Zone Research, Chinese Academy of Sciences, Yantai 264003, China \\ * Correspondence: lgxu@niglas.ac.cn (L.X.); xbchen@yic.ac.cn (X.C.); Tel.: +86-15366051586 (L.X.); \\ +86-18615032702 (X.C.); Fax: +86-025-8688-2105 (L.X.); +86-053-5210-9111 (X.C.)
}

Received: 28 September 2020; Accepted: 28 October 2020; Published: 30 October 2020

\begin{abstract}
Purpose: The Yellow River delta boasts rich land resources but lacks fresh water and exhibits poor natural conditions. To rationally develop and utilize the land resources therein, it is necessary to evaluate the soil quality. Methods: Adopting specific screening conditions, principal component analysis (PCA) was used to construct a minimum data set (MDS) from 10 soil indicators. Then, a complete soil quality evaluation index system of the Yellow River delta was developed. The soil quality comprehensive index (SQI) method was used to assess the soil quality in the Kenli District, and the soil quality grades and spatial distribution were analyzed. Results: (1) The average SQI of the Kenli District is 0.523 , and the best soil quality is concentrated near the Yellow River, especially in Huanghekou town. (2) The normalized difference vegetation index was positively correlate with SQI, whereas $\mathrm{Dr}$ (nearest distance between the sampling site and Yellow River) and Ds (nearest distance between the sampling site and Bohai Sea) were negatively correlated with SQI. Elev (sampling site elevation) was not correlated with SQI. (3) The SQI of agricultural planting is greater than that of the natural land type and significantly greater than that of nudation. The main factors limiting farmland soil quality are SK (water-soluble potassium) and $\mathrm{pH}$, whereas the factor limiting the natural land type are the soil nutrient indicators. Conclusions: To improve soil quality and develop and utilize land resources, the towns should adopt systematic land development/utilization methods based on local conditions. These results have important guiding significance and practical value for the more objective and accurate evaluation of soil quality in coastal areas and the development and utilization of land resources.
\end{abstract}

Keywords: evaluation indicator screening; external environment; soil quality assessment; soil quality management

\section{Introduction}

Soil, air and water, are integral components of our environment [1-3]. Soil can support the growth of plants and animals, maintain and improve the quality of water and air, and provide adequate shelter for humans in both natural and unnatural ecosystems. Some scholars define soil's ability to achieve these functions as soil quality [4]. Understanding soil quality is important to improving sustainable land use management [5], providing early warning signals of adverse trends in soil quality change, identifying problematic areas of soil quality [6], and providing a valuable basis for the subsequent 
rational use and improvement of soil [7]. However, these understanding can only be obtained through reliable and accurate soil quality evaluation methods. Soil quality evaluation refers to the monitoring and evaluation of soil properties, soil functions and soil conditions.

Accurate evaluation of soil quality is difficult given the heterogeneity and variabilities in the physical, chemical and biological characteristics of soil in different regions [8-10], and the use of pesticides and fertilizers and different soil management measures further complicate the evaluation [11]. In addition, the soil quality evaluation is often confused with soil fertility evaluation. Thus, in the process of a soil quality assessment on soil fertility status [12], the limiting factors of soil quality vary according to the type of land use, the geographical location of the ecosystem and the soil parent material $[13,14]$. At present, there are no recognized norms or standards used to establish soil quality evaluation index systems or soil quality classifications $[15,16]$. Based on the variability and complexity of soil properties, a variety of soil quality evaluation methods have been developed, such as the soil quality index (SQI) [17,18], fuzzy association rules [19], the dynamic soil quality model [20], the soil management evaluation framework [21], and the soil quality card and detection kit [22]. Among these methods, the SQI is widely used because it can be applied to flexibly quantify different soil types and can flexibly integrate the physical, chemical and biological properties of soil [15]. The quantitative calculation method of soil quality index adopts three steps: indicator selection, indicators scoring and comprehensive score into one index [14,23,24].

By establishing the minimum data set (MDS), we can easily select the most appropriate indicator to evaluate soil quality, and this indicator has been used widely $[4,25,26]$. The selection of MDS indictors can reduce the redundancy of soil data. In addition, the weight of selected indicators can be calculated while establishing the MDS, thus reducing the subjective influence [27]. MDS can be screened by linear and multiple regression factor analysis, discriminant analysis and score function. Because a factor analysis can reduce redundant information in the original data set, it is widely used in the identification of the MDS [28]. For example, Peng Li used a one-way analysis of variance (ANOVA) and factor analysis to select four of 26 soil indicators and built an MDS to evaluate soil quality in different wheat-producing areas of China [4]. Research on soil quality assessments based on MDS have been effectively applied and promoted in different land use types, such as offshore areas [28,29], agricultural areas $[8,15]$ and grasslands [27]. Considering the external environment and human management influence on soil quality, some scholars have attempted to add macro soil environmental factors and land use status into the indicator selection criteria to improve the establishment of the MDS and have achieved good results, however, this method has not been widely used [30,31].

The Yellow River delta was mainly formed by sediment deposition from the Yellow River [32]. A large number of nutrients are carried by the sediment in the upper reaches of the Yellow River. However, these nutrients are simultaneously affected by seawater intrusion, and soil salinization is becoming increasingly serious [33]. In addition, in recent decades, there have been frequent human activities such as oil extraction, cultivation and urban construction in the Yellow River delta [32,34]. Moreover, water inflow from the upper reaches of the Yellow River decreases every year, and coastal wetlands have significantly degraded [34]. Influenced by natural conditions and human activities, natural ecosystems have been degraded by artificial isolation [32]. Overall, the soil quality has deteriorated, but in some areas, soil quality has been improved by tillage, which results in the great variation in soil quality in the Yellow River delta [31]. These problems in the Yellow River delta hinterland, the Yellow River estuary Kenli District, are particularly obvious. In recent years, studies of soil quality in the Yellow River delta have been relatively limited. In addition, some problems were noted with previous studies. The Yellow River and the ocean are important regional features of the Yellow River delta; however, previous studies on soil quality in this region have not considered the impact of external factors, such as the Yellow River and coastline, on soil quality [35]. Moreover, relevant studies are not comprehensive or scientific in nature.

The objective of this study was to evaluate the soil quality of the typical coastal area of the Yellow River delta-Kenli District based on the MDS method. The vegetation normalization index, the distance 
from sampling points to the Yellow River and the coastline and elevations of sampling points were considered the influential factors in the indicator screening process. This study attempted to find out the limiting factors of the soil quality characteristics of different land use types and towns, as well as the correlations between the external environment factors and soil quality, some of which were firstly studied in the Yellow River delta. The results of this study have important guiding significance and practical value for objectively and accurately evaluating the soil quality of reclamation areas in coastal areas.

\section{Materials and Methods}

\subsection{Study Area}

The Yellow River delta wetland is the largest, most complete and youngest estuarine wetland ecosystem preserved in the warm temperate zone of the world. The delta is formed by the interaction of the Yellow River alluvium and marine deposition, with loose lithology and low and flat terrain. The region has a subhumid continental monsoon climate with four distinct seasons and rainy summers. The average annual temperature is $12.9^{\circ} \mathrm{C}$, and the average annual precipitation is $560 \mathrm{~mm}, 70 \%$ of which occurs from July to September [33]. The average annual evaporation rate is $1900-2400 \mathrm{~mm}$, with an evaporation precipitation ratio greater than 3.5 [32]. Affected by tides and Yellow River runoff [36], the average groundwater level in this area is $1.1 \mathrm{~m} \mathrm{[32],} \mathrm{and} \mathrm{the} \mathrm{average} \mathrm{groundwater}$ salinity is $30.1 \mathrm{~g} / \mathrm{L}$ [37].

The Kenli District in Dongying city of Shandong Province was selected as the research area. The Kenli District is located at the estuary of the Yellow River in the hinterland of the Yellow River delta. The regional location is $37^{\circ} 24^{\prime}-38^{\circ} 10^{\prime} \mathrm{N}, 118^{\circ} 15^{\prime}-119^{\circ} 19^{\prime}$ E. Due to its low elevation (generally less than $10 \mathrm{~m}$ except for roads and levees) and proximity to the ocean, the hydrological characteristics of the Kenli District are affected by the interactions between freshwater and seawater, as well as between groundwater and surface water [34]. Due to the large evaporation precipitation ratio, high groundwater level and salinity, soil salinization in the study area is a more serious problem. Repeated breaches that have been diverted from the Yellow River have resulted in the regional formation of hillocks, slopes, depressions and landforms. In addition, due to human activities, such as the artificial diversion of the Yellow River, Yellow River levee and coastal levee building, oil exploitation, urban construction, and farming techniques allowed on the delta, great changes have occurred in these micro landforms. These changes determine surface runoff and groundwater movement, forming the water and salt gathering area with the depression as the center and a "post drought, hollow waterlogging and the second slope basification" phenomenon. Due to its unique geographical location, in a normal year, the Yellow River can produce approximately $20 \mathrm{~km}^{2}$ of new land by carrying sand. The Yellow River sediment brings a large amount of nutrients from the upstream to the Kenli District. The main natural vegetation in this area is reeds (Phragmites australis), Tamarix chinensis, and Spartina alterniflora. Artificial vegetation mainly includes cotton, corn, rice, wheat, legume and white wax.

\subsection{Data Collection}

Before the on-site sampling was conducted, a total of 149 sampling points were set up evenly in the Kenli District and nearby areas at the shortest distance of $2 \mathrm{~km}$ by using Google Earth software and the visual interpretation method. Then, the WGS84 coordinates of the designed sampling points were imported into a handheld GPS navigator. Field sampling was conducted according to the predetermined location of sampling points and the field conditions. Soil drills with a diameter of $5 \mathrm{~cm}$ were used to collect the surface soil at $0-20 \mathrm{~cm}$ in 3 places within a range of $3 \mathrm{~m}$ from each point. After mixing, the samples were sealed in bags and numbered. A handheld GPS navigator was used to record the exact longitudes and latitudes of the sampling points, and the land use types, vegetation, hydrological characteristics and topography around the sampling points were also recorded. Finally, a total of 127 sampling points fall within the scope of the Kenli District (point position distribution 
is shown in Figure 1), and a total of 9 planting cover types were sampled in 7 townships (Table 1). Because most of the soil is flooded by the seawater, there are no sampling points in the intertidal zone, and the study area does not include the intertidal zone. To ensure the reliability of the statistical analysis, a comparative analysis is not conducted for vegetation types with fewer than 6 sampling sites, and a statistical comparative analysis is not conducted for towns with less than 8 sampling sites.

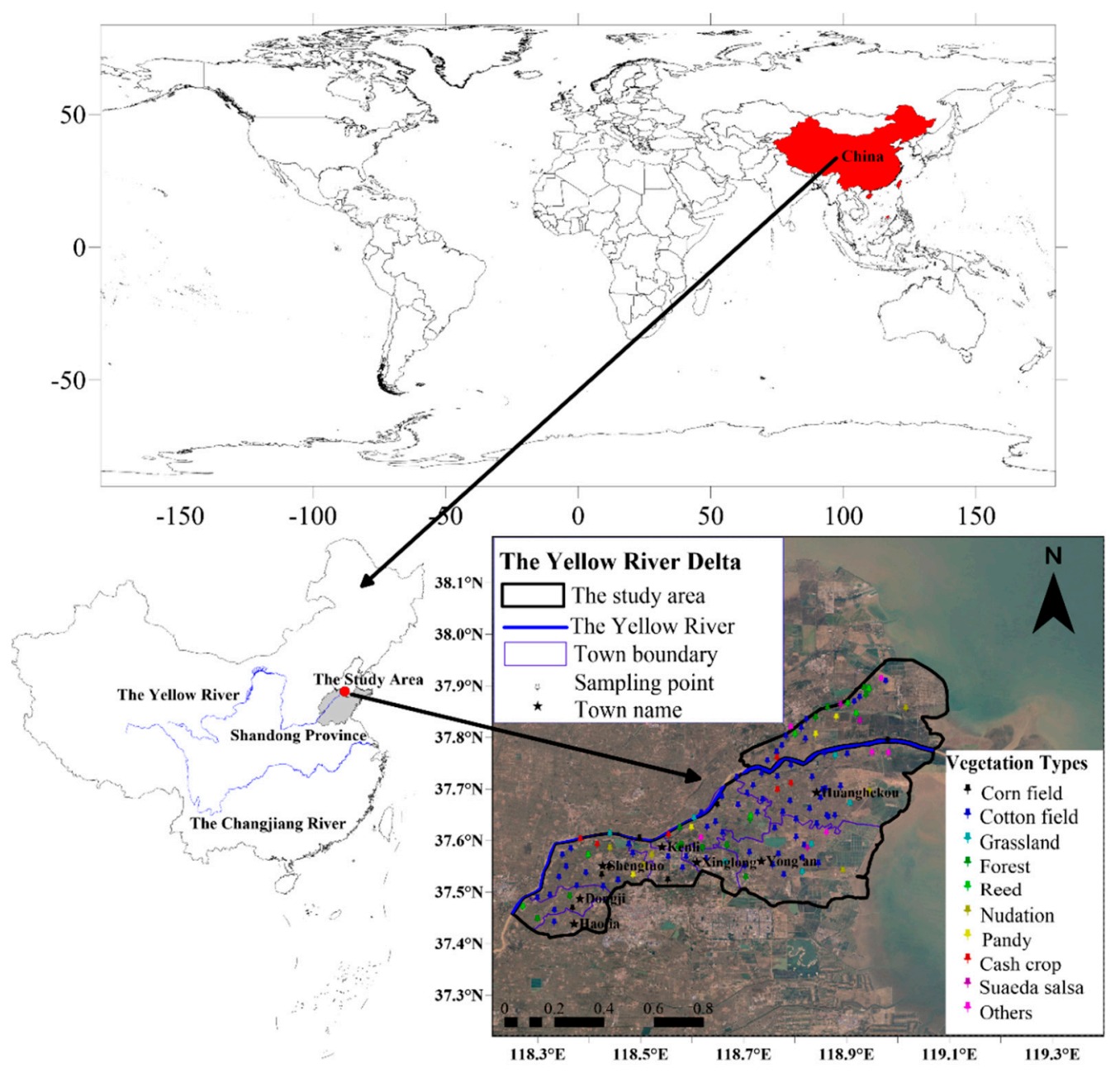

Figure 1. Geographic locations of soil sampling sites with different vegetation types.

Table 1. The numbers of sampling points in different vegetation types and towns.

\begin{tabular}{ccccccccc}
\hline Vegetation Types & Huanghekou & Yong'an & Kenli & Xinglong & Shengtuo & Dongji & Haoji & Sum \\
\hline Cash crop & 2 & 0 & 1 & 0 & 2 & 0 & 0 & 5 \\
Corn field & 1 & 0 & 3 & 0 & 2 & 0 & 1 & 7 \\
Cotton field & 26 & 13 & 13 & 1 & 7 & 5 & 1 & 66 \\
Forest & 5 & 2 & 4 & 1 & 0 & 2 & 0 & 14 \\
Grass & 2 & 1 & 1 & 1 & 1 & 0 & 0 & 6 \\
Nudation & 2 & 1 & 1 & 0 & 2 & 0 & 0 & 6 \\
Others & 5 & 3 & 1 & 0 & 1 & 0 & 0 & 10 \\
Paddy land & 2 & 0 & 1 & 0 & 1 & 0 & 0 & 4 \\
Reed & 4 & 0 & 1 & 0 & 1 & 1 & 0 & 7 \\
Suaeda salsa & 2 & 0 & 0 & 0 & 0 & 0 & 0 & 2 \\
Sum & 51 & 20 & 26 & 3 & 17 & 8 & 2 & 127 \\
\hline
\end{tabular}




\subsubsection{Soil Sample Analysis}

The collected soil samples were naturally air-dried in the laboratory, and the roots and other sundries were removed. Then, the soil samples were ground and sifted through a 1-mm sieve. The ground soil samples were accurately weighed to $6.0000 \mathrm{~g}$, and placed in a centrifuge tube. Then, $30 \mathrm{~mL}$ of deionized water was added. After oscillating on the oscillator for $5 \mathrm{~min}$, the samples were centrifuged at 10,000 r/min for $5 \mathrm{~min}$. Then, the supernatant was extracted to prepare the soil extract with a soil to water ratio of 1:5. Partial soil chemical parameters were determined using the method described in the literature [38]: The $\mathrm{pH}$ of the soil extract was determined by a PHSJ-4A pH meter, and the conductivity of the extract (EC) was determined using a DDSJ-308A conductivity meter. The soil organic matter $(\mathrm{OM})$ was determined using the potassium dichromate external heating method. The soil extract obtained by centrifugation was diluted by $2 \mathrm{~mL} 20$ times and then sent to the testing and analysis center of the Yantai Institute of the Coastal Zone, Chinese Academy of Sciences for ion concentration determination. The concentrations of $\mathrm{NH}_{4}{ }^{+}, \mathrm{NO}_{3}{ }^{-}, \mathrm{Cl}^{-}, \mathrm{Na}^{+}, \mathrm{SO}_{4}{ }^{2-}, \mathrm{K}^{+}, \mathrm{Ca}^{2+}$, and $\mathrm{Mg}^{2+}$ in solution were determined by a Dionex ICS3000 ion chromatograph. The sum of the mass of $\mathrm{NH}_{4}^{+}$ and $\mathrm{NO}_{3}{ }^{-}$was used to represent the soil available nitrogen (AN), and $\mathrm{K}^{+}$was the soil water-soluble potassium (SK).

\subsubsection{The Auxiliary Data}

The auxiliary data are used as the influencing factor of the external environment in the indicator screening process $[39,40]$, including the altitude of the sampling point (Elev, the data are obtained from Google Earth geodesic elevation, and the sampling interval is $7.57 \mathrm{~m}$ ), Normalized Difference Vegetation Index (NDVI, data were extracted from Landsat 8 OLI at a sampling interval of $30 \mathrm{~m}$ ), the nearest straight-line distance between the sampling point and the Yellow River (Dr, data were obtained by using ArcMap c after linear vectorization of the Yellow River), the nearest straight-line distance between the sampling point and the coastline (Ds, data were obtained using ArcMap nearest neighbor analysis after linear vectorization of the coastline) [41]. All data sets are projected into a universal transverse Mercator Cartesian projection coordinate system based on WGS84 (the EPSG code is 32650).

\subsection{Methods of Soil Quality Assessment}

Soil quality index was calculated by four steps (Figure 2). Firstly, correlation analysis is carried out to determine whether the soil indicators were redundant. Secondly, principal component analysis and external environmental indicators are combined to screen the minimum data set (MDS) and obtain their weights. Thirdly, standard scoring functions (SSF) were used to score the MDS. Finally, the soil quality index is calculated according to the indicator score and its weight. The specific processes are described as follows.

\subsubsection{Determine the MDS}

Soil quality assessment is based on the selection of representative soil indicators. We used principal component analysis (PCA) among soil indicators and linear regression coefficients between them and external environmental factors to determine the appropriate MDS for soil quality assessment [31].

First, the grouping of evaluation indicators was determined. A Pearson correlation analysis was performed on soil indicators to analyze whether collinearity existed between indicators and determine whether it was necessary to screen out all the indicators from preselected indicators. If there is redundancy in the soil indicators, a PCA is used to group the indicators, with the component of the eigenvalue $\geq 1$ as the main component. Indicators in the same principal component with a factor load of $\geq 0.5$ were placed into one group. If the factor loads of a certain indicator in different principal components are all $\geq 0.5$, the indicator was placed into the group with the lowest correlation with other indicators. If the correlation coefficient between an indicator and other indicators in a group is less 
than 0.3 , then the indicator is placed into a separate group. Here, the indicator grouping has been determined and completed.

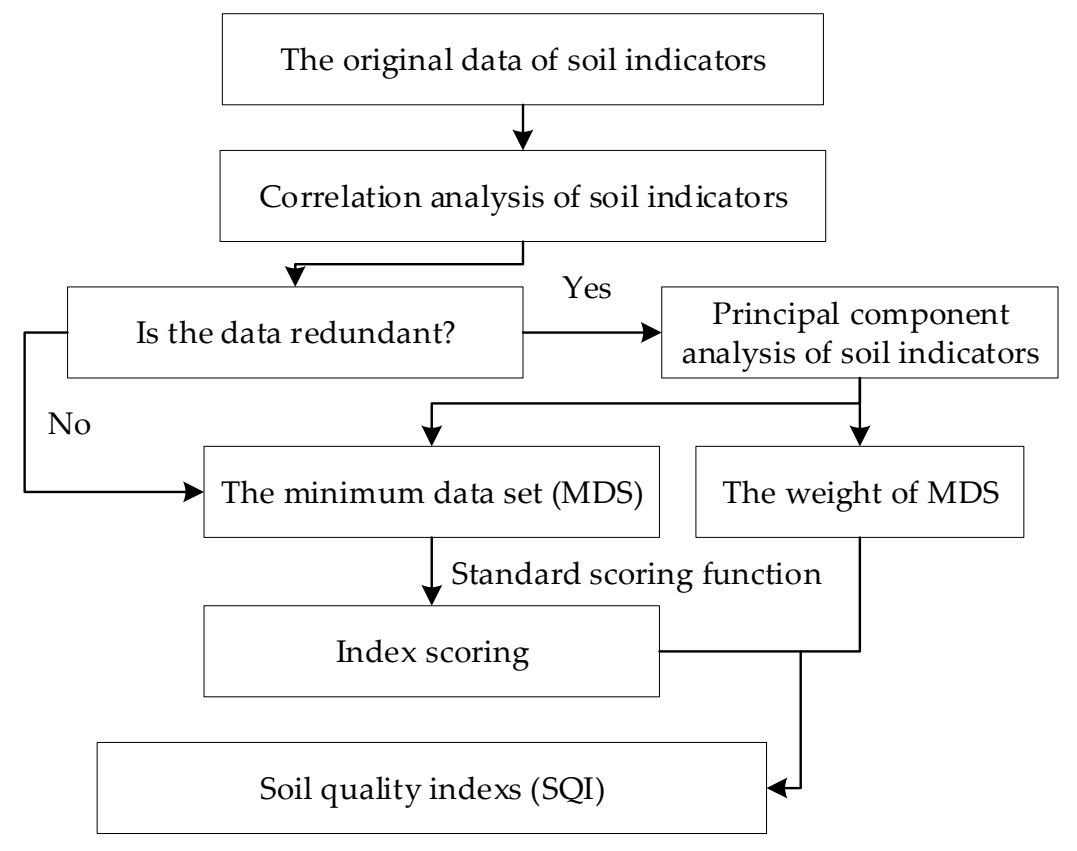

Figure 2. Flowchart of the study procedure.

Then, the MDS is determined by calculating the indicator values of each indicator. The indicator vector norm is calculated as noted in Formula (1). Considering that soil quality is determined by both internal properties and the external environment [42], the elevation of sampling points (Elev), NDVI, distance to the Yellow River (Dr) and distance to the coastline (Ds) were added as the screening criteria in this study. Through a regression analysis, the coefficient of determination $\left(R^{2}\right)$ between the factors influencing the external environment and each indicator was obtained, and $R^{2}$ reflected the degree of influence of the external environment on the soil indicators. Then, the vector norm of each indicator and the determination coefficient $R^{2}$ are summed by the standard linear transformation to obtain the indicator value. The indicators set to at least $90 \%$ of the maximum indicator value in each group are the preselected indicators. If the correlation coefficient of any two preselected indicators is greater than 0.5 , then the indicator with the higher indicator value is selected for the MDS. Otherwise, all metrics are selected as MDS.

$$
N_{i}=\sqrt{\sum_{j=1}^{k} u_{i j}^{2} \lambda_{j}}
$$

$N_{i}$ is the combined load of indicator $i$ in all components with eigenvalues $\geq 1, u_{i j}$ is the load of indicator $i$ in principal component $j$, and $\lambda_{j}$ is the eigenvalue of the principal component $j$.

\subsubsection{Weight Allocation}

After the MDS indicator is determined, the weight of each MDS indicator is the ratio of the common factor variance in the PCA to the sum of the common factor variance in all MDS indicators.

\subsubsection{Indicator Scoring}

After determining the indicators of the MDS, each indicator was converted using a standard scoring function (SSF), which was normalized to a value between 0.1 and 1 according to the characteristics of the soil indicators [43]. Generally, the indicators' scoring functions follow "more is better", "less is 
better" or "optimum" scoring curve trends. Equations (2)-(4) were used for scoring of "more is better", "optimum" and "less is better" curves, respectively:

$$
\begin{gathered}
\text { SSF1 }: f(x)=\left\{\begin{array}{c}
0.1, x<L \\
0.1+\frac{0.9 \times(x-L)}{(U-L)}, L \leq x \leq U \\
1.0, x>u
\end{array}\right. \\
\text { SSF2 : } f(x)=\left\{\begin{array}{c}
0.1, x\left\langle L_{1}, x\right\rangle U_{2} \\
0.1+\frac{0.9 \times\left(x-L_{1}\right)}{\left(U_{1}-L_{1}\right)}, L_{1} \leq x \leq U_{1} \\
1.0, U_{1}<x<L_{2} \\
0.1+\frac{0.9 \times\left(U_{2}-x\right)}{\left(U_{2}-L_{2}\right)}, L_{2} \leq x \leq U_{2} \\
1, x<L
\end{array}\right. \\
\text { SSF3 : } f(x)=\left\{\begin{array}{c}
0.9 \times(U-x) \\
0.1+\frac{0.9 \leq x \leq U}{(U-L)}, L \\
0.1, x>U
\end{array}\right.
\end{gathered}
$$

where $x$ is the measured value of the soil indicator, $f(x)$ is the score of the soil indicator, and $U$ and $L$ are the upper and lower critical values of the soil indicator, respectively.

\subsubsection{SQI Calculation Method}

Finally, SQI was calculated according to Formula (5) [44]:

$$
\mathrm{SQI}=\sum_{1}^{n}\left(W_{i} \times S_{i}\right)
$$

where $W_{i}$ is the weight of indicator $i ; S_{i}$ is the score of indicator $i$, which was calculated according to $\mathrm{SSF}$; and $n$ is the indicator number of the MDS.

\subsection{Statistical Analysis}

SPSS 25.0 was used for the statistical analysis. The Kolmogorov-Smirnov test (K-S normal test) was used for data normality testing. The Pearson product difference correlation test (bilateral) was used for the correlation analysis. PCA analysis was used to group soil indicators. A one-way ANOVA was used to quantitatively analyze the differences in SQIs of different vegetation types and different townships. A linear regression is used to quantify the influence of external factors on soil indicators and soil quality. To test the interpolation accuracy, 16 methods were used in this study: simple to quartic inverse distance weight (IDW), global first degree polynomial (GP), simple to quartic local polynomials (LP), tension spline interpolation (SPT), regular spline interpolation (CRS), higher-order surface function interpolation (MTQ), inverse higher-order surface function interpolation (IMTQ), thin plate spline function interpolation, simple kriging (SK) and ordinary kriging interpolation (OK). The interpolation diagram was drawn by Golden Software Surfer 15.0 [45], and the other figures were generated using Python 3.7 Pandas, matplotlib, and seaborn.

\section{Results}

\subsection{The Characteristics and Spatial Variation Description of Soil in the Kenli District}

Ten soil characteristics and four external environmental factors related to soil quality were measured and analyzed (Table 2). Values of $\mathrm{pH}, \mathrm{OM}$ and all four external environmental factors (NDVI, Elev, Ds, and Dr) passed the K-S normal test. From the spatial position of the sampling points, the nearest points to the Yellow River and the coastline are only 464 and $1040 \mathrm{~m}$, respectively, and the farthest are 24.8 and $55.7 \mathrm{~km}$, respectively. The elevations of the sampling points range from -0.94 to $12.37 \mathrm{~m}$. The average $\mathrm{OM}$ was $10.15 \mathrm{~g} / \mathrm{kg}$, and the maximum OM was $21.77 \mathrm{~g} / \mathrm{kg}$. The average $\mathrm{pH}$ 
of the soil was 8.50, which was considered to be a weakly alkaline soil with a weak spatial variation. Other soil indicators (EC, $\mathrm{AN}, \mathrm{Cl}^{-}, \mathrm{Na}^{+}, \mathrm{SO}_{4}{ }^{2-}, \mathrm{Ca}^{2+}, \mathrm{Mg}^{2+}$, and $\mathrm{SK}$ ) are lognormal, and the large standard error and high data dispersion indicate that the spatial variation in these soil indicators is large. Table 2 demonstrates that the maximum value of the indicator is much greater than the upper quantile, indicating a high degree of data dispersion.

Table 2. Descriptive statistics of the soil properties and external environmental factors.

\begin{tabular}{cccccccc}
\hline Variables & Mean & SE & Min & Q1 & Median & Q3 & Max \\
\hline NDVI & 0.50 & 0.01 & 0.13 & 0.39 & 0.51 & 0.59 & 0.82 \\
Elev & 4.45 & 0.23 & -0.94 & 2.71 & 4.50 & 6.17 & 12.37 \\
Ds & 23,276 & 1201.46 & 1040 & 12,204 & 20,743 & 30,374 & 55,683 \\
Dr & 7360 & 468.48 & 464 & 3080 & 6418 & 10,547 & 24,817 \\
OM $(\mathrm{g} / \mathrm{kg})$ & 10.15 & 0.38 & 1.19 & 6.85 & 10.17 & 12.48 & 21.77 \\
pH & 8.50 & 0.02 & 7.91 & 8.35 & 8.49 & 8.65 & 9.31 \\
EC (mS/cm) & 0.74 & 0.19 & 0.08 & 0.28 & 0.66 & 1.65 & 10.26 \\
$\mathrm{AN}(\mathrm{mg} / \mathrm{kg})$ & 56.59 & 8.14 & 9.83 & 33.97 & 49.30 & 90.45 & 503.13 \\
$\mathrm{Cl}(\mathrm{mg} / \mathrm{kg})$ & 462.76 & 359.57 & 18.76 & 79.76 & 520.97 & 1866.50 & $20,303.66$ \\
$\mathrm{SO} 4(\mathrm{mg} / \mathrm{kg})$ & 328.89 & 55.23 & 32.47 & 167.62 & 345.98 & 709.29 & 5634.49 \\
$\mathrm{Na}(\mathrm{mg} / \mathrm{kg})$ & 339.35 & 153.57 & 20.51 & 104.30 & 359.18 & 1017.57 & 9378.79 \\
$\mathrm{Mg}(\mathrm{mg} / \mathrm{kg})$ & 43.66 & 24.74 & 4.13 & 14.13 & 28.03 & 105.12 & 1746.39 \\
$\mathrm{Ca}(\mathrm{mg} / \mathrm{kg})$ & 157.14 & 35.97 & 26.19 & 78.92 & 145.07 & 281.40 & 3237.80 \\
$\mathrm{SK}(\mathrm{mg} / \mathrm{kg})$ & 15.99 & 3.68 & 2.55 & 9.53 & 15.48 & 22.43 & 258.96 \\
\hline
\end{tabular}

(Where Mean is the average, $\mathrm{SE}$ is standard error, Min is minimum value, Max is maximum value, Q1 and Q3 are the upper and lower quartiles, respectively Because $\mathrm{EC}, \mathrm{AN}, \mathrm{Cl}^{-}, \mathrm{Na}^{+}, \mathrm{SO}_{4}{ }^{2-}, \mathrm{Ca}^{2+}, \mathrm{Mg}^{2+}$, and $\mathrm{SK}$ do not obey a normal distribution, the mean is represented by geometric mean. Elev is the altitude of the sampling point, NDVI is normalized difference vegetation index, Dr and Ds represent the nearest straight-line distance from the sampling point to the Yellow River and the coastline, respectively, and the meaning of these abbreviations is the same in the tables and figures below).

\subsection{MDS Selection and SQI Calculation}

\subsubsection{MDS Selection}

The Pearson correlation coefficients of all soil character indicators (Figure 3), including EC, $\mathrm{Cl}^{-}, \mathrm{Na}^{+}, \mathrm{SO}_{4}{ }^{2-}, \mathrm{Ca}^{2+}$, and $\mathrm{Mg}^{2+}$, were significantly correlated with each other, and the correlation coefficient was greater 0.7. The correlation coefficient among EC, $\mathrm{Cl}^{-}$and $\mathrm{Na}^{+}$was greater than 0.97 , which indicates that $\mathrm{Cl}^{-}$and $\mathrm{Na}^{+}$are the most important ions affecting soil salinity and that seawater salinity is the main source of soil salinity. The $\mathrm{pH}$ was negatively correlated with all the indicators, and the correlation coefficients were the highest with $\mathrm{Mg}^{2+}$ and $\mathrm{Ca}^{2+}$, which were 0.63 and 0.73 , respectively, indicating that it was feasible to add calcium and magnesium modifiers to reduce the $\mathrm{pH}$ of the saline soil. OM and AN are not significantly correlated with most soil indicators. OM is only significantly negatively correlated with $\mathrm{pH}$ and $\mathrm{Cl}$, but the correlation coefficient is low $(0.24$ and 0.17 , respectively), indicating that soil salinity has no significant relationship with $\mathrm{OM}$. AN is only significantly correlated with $\mathrm{SK}, \mathrm{Ca}^{2+}$ and $\mathrm{pH}$, but the correlation coefficient is relatively low at between 0.1 and 0.25 . We divided the clustering results into five categories: "SK", "OM", "AN", "EC, $\mathrm{Cl}^{-}, \mathrm{Na}^{+}, \mathrm{SO}_{4}{ }^{2-}, \mathrm{Ca}^{2+}, \mathrm{Mg}^{2+}$ ", and " $\mathrm{pH}^{\prime}$. The classification results represent soil fertility properties (potassium, nitrogen, and organic matter, which are the first three categories), salinity characteristics (conductivity and salt ions, the fourth category) and acid-base properties ( $\mathrm{pH}$, the fifth category). The correlation analysis results reveal that $\mathrm{EC}, \mathrm{Cl}^{-}, \mathrm{Na}^{+}, \mathrm{SO}_{4}{ }^{2-}, \mathrm{Ca}^{2+}, \mathrm{Mg}^{2+}$ and $\mathrm{SK}$ are collinear with each other, and redundancy is noted in the interpretation of soil properties. Therefore, it is necessary to eliminate some indicators in the process of establishing the MDS. 


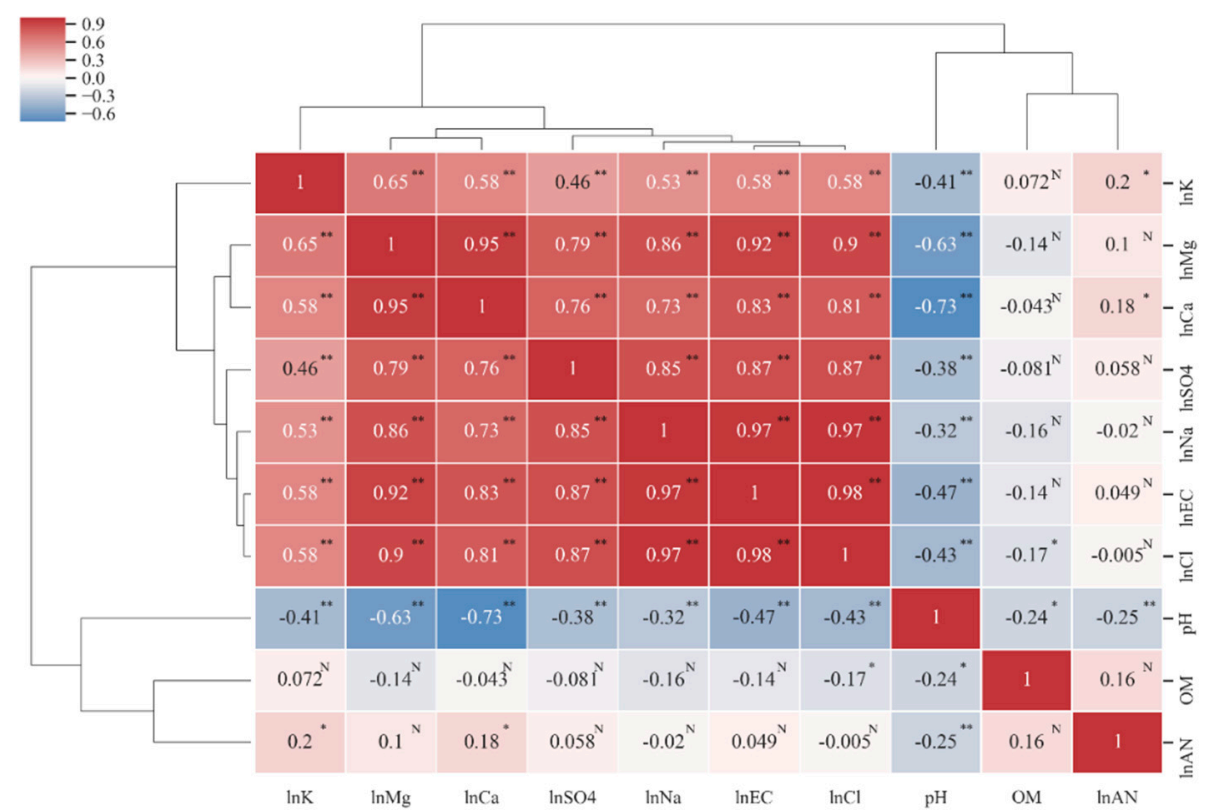

Figure 3. Cluster-Pearson correlation coefficient heat map among soil properties. ${ }^{*}$ Indicates significance level at $p \leq 0.05$. ${ }^{* *}$ Indicates significance level at $p \leq 0.01$. N indicates no significance. The Pearson correlation analysis requires factors to conform to a normal distribution, so a natural logarithmic transformation is used for indicators that do not conform to a normal distribution.

Further, we used the PCA to select an MDS from 10 soil indicators [44]. Three principal components (PCs) that had an eigenvalue of $>1$, and the cumulative variance interpretation rate is $80.226 \%$. In PC1, there are 7 indicator factor loads greater than 0.5 , which are mainly related to soil salinity properties. In PC2, pH, AN and OM were the high weight variables, accounting for $26.68 \%$ of the variation. In PC3, AN and SK are high weighted variables that represent the nutrient status of soil. Then, all the indicators were divided into five groups according to the above grouping criteria.

The vector norm values (norm) of each indicator are calculated according to Formula (1) and the eigenvalues and factor loads are listed in Table 3. The Pearson correlation coefficient between the soil indicators and external environmental factors (Elev, NDVI, Dr, and Ds) was obtained by SPSS correlation analysis (Table 4). The analysis results demonstrate that $\mathrm{EC}, \mathrm{Na}^{+}, \mathrm{Cl}^{-}$and $\mathrm{SK}$, the four ions that can represent soil salinity, are significantly correlated with the four external environmental factors: they are positively correlated with Elev, NDVI and Ds and negatively correlated with Dr. No significant correlation was noted among AN, OM and external environmental factors, indicating that the distance between the elevation of vegetation coverage and the coastline of the Yellow River did not affect the distributions of AN and OM. pH was significantly positively and negatively correlated with Ds and Dr, respectively, with a correlation coefficient of 0.24 . However, this correlation was not related to NDVI or altitude, indicating that seawater would increase the soil alkalinity, whereas fresh water could improve the soil alkalinity [46]. Except for OM and SK, the correlation coefficients of Ds, Dr and other soil indicators are very similar, indicating that the influence of seawater and the Yellow River on most of the soil chemical properties is negative and equivalent. No significant correlation exists between the indicator and the external environment, the coefficient of determination is 0 . Finally, according to the above MDS screening method, the MDS included the five indicators of $\mathrm{Na}, \mathrm{OM}, \mathrm{pH}$, AN, and SK (Table 5). 
Table 3. Results of PCA for soil quality indicators.

\begin{tabular}{cccc}
\hline PCs & PC1 & PC2 & PC3 \\
\hline Eigenvalue & 5.595 & 1.379 & 1.048 \\
Percent & 55.947 & 13.794 & 10.485 \\
Cumulative percent & 55.947 & 69.741 & 80.226 \\
Eigenvectors & & & \\
Cl & $\underline{0.966}$ & -0.144 & 0.036 \\
SO4 & $\underline{0.817}$ & 0.013 & -0.140 \\
Na & $\underline{0.909}$ & -0.194 & 0.132 \\
Mg & $\underline{\underline{0.969}}$ & -0.053 & -0.104 \\
Ca & $\underline{\underline{0.867}}$ & 0.107 & -0.261 \\
EC 1:5 & $\underline{\underline{0.970}}$ & -0.103 & 0.028 \\
pH & $\underline{-0.495}$ & $\underline{-0.611}$ & 0.288 \\
AN & 0.055 & $\underline{0.661}$ & $\underline{0.560}$ \\
SK & $\underline{0.529}$ & 0.167 & $\underline{0.637}$ \\
OM & -0.095 & $\underline{0.677}$ & -0.358 \\
\hline
\end{tabular}

Table 4. The coefficient of determination $\left(R^{2}\right)$ between the indicators and external environment.

\begin{tabular}{|c|c|c|c|c|c|c|c|c|c|c|c|c|c|c|}
\hline Indicators & NDVI & Elev & Ds & Dr & OM & $\mathrm{pH}$ & $\ln E C$ & $\ln A N$ & $\operatorname{lnCl}$ & $\ln \mathrm{SO} 4$ & $\operatorname{lnNa}$ & $\operatorname{lnMg}$ & $\ln C a$ & $\ln K$ \\
\hline NDVI & 1 & 0.01 & -0.08 & -0.11 & 0.15 & 0.03 & $-0.21 *$ & 0.14 & $-0.20 *$ & -0.09 & $-0.22 *$ & -0.15 & -0.06 & -0.21 * \\
\hline Elev & 0.01 & 1 & $0.75^{* *}$ & $-0.36^{* *}$ & -0.14 & 0.17 & $-0.26^{* *}$ & 0.03 & $-0.30^{* *}$ & $-0.21 *$ & $-0.31^{* *}$ & $-0.29 * *$ & $-0.24^{* *}$ & -0.30 ** \\
\hline Ds & -0.08 & $0.75^{* *}$ & 1 & $-0.36^{* *}$ & -0.14 & $0.24^{* *}$ & $-0.22 *$ & -0.11 & $-0.24^{* *}$ & -0.16 & $-0.24^{* *}$ & $-0.32 * *$ & $-0.28^{* *}$ & -0.42 ** \\
\hline Dr & -0.11 & $-0.36^{* *}$ & $-0.36^{* *}$ & 1 & -0.05 & $-0.24 * *$ & $0.26 * *$ & -0.08 & $0.27 * *$ & 0.16 & $0.26 * *$ & $0.31^{* *}$ & $0.27 * *$ & $0.25 * *$ \\
\hline
\end{tabular}

Table 5. Indicators included in the MDS

\begin{tabular}{|c|c|c|c|c|c|c|c|c|c|c|c|c|c|}
\hline \multirow{2}{*}{ Group } & \multirow{2}{*}{ Indicator } & \multirow{2}{*}{ Norm } & \multicolumn{4}{|c|}{$\mathbf{R}^{2}$} & \multicolumn{5}{|c|}{ Normal Transformation } & \multirow{2}{*}{ Value } & \multirow{2}{*}{ Included } \\
\hline & & & NDVI & Elev & Ds & Dr & Norm & NDVI & Elev & Ds & Dr & & \\
\hline 1 & $\mathrm{EC}_{1: 5}$ & 2.31 & 0.08 & 0.10 & 0.10 & 0.13 & 1.00 & 0.72 & 0.91 & 0.87 & 0.83 & 4.33 & No \\
\hline 1 & $\mathrm{Cl}$ & 2.30 & 0.09 & 0.10 & 0.11 & 0.15 & 1.00 & 0.84 & 0.97 & 1.00 & 0.96 & 4.77 & No \\
\hline 1 & $\mathrm{SO}_{4}$ & 1.93 & 0 & 0.03 & 0 & 0 & 0.84 & 0 & 0.27 & 0 & 0 & 1.11 & No \\
\hline 1 & $\mathrm{Na}$ & 2.18 & 0.11 & 0.11 & 0.11 & 0.15 & 0.94 & 1.00 & 1.00 & 0.97 & 1.00 & 4.91 & Yes \\
\hline 1 & $\mathrm{Mg}$ & 2.30 & 0 & 0.08 & 0.10 & 0.11 & 1.00 & 0 & 0.71 & 0.90 & 0.69 & 3.29 & No \\
\hline 1 & $\mathrm{Ca}$ & 2.08 & 0 & 0.04 & 0.05 & 0.05 & 0.90 & 0 & 0.39 & 0.48 & 0.35 & 2.12 & No \\
\hline 2 & $\mathrm{OM}$ & 0.92 & 0 & 0 & 0 & 0 & 0.40 & 0 & 0 & 0 & 0 & 0.40 & Yes \\
\hline 3 & $\mathrm{pH}$ & 1.43 & 0 & 0 & 0.06 & 0.06 & 0.62 & 0 & 0 & 0.52 & 0.38 & 1.14 & Yes \\
\hline 4 & AN & 0.99 & 0 & 0 & 0 & 0 & 0.43 & 0 & 0 & 0 & 0 & 0.43 & Yes \\
\hline 5 & SK & 1.43 & 0.08 & 0.03 & 0.07 & 0.05 & 0.62 & 0.69 & 0.31 & 0.62 & 0.33 & 2.24 & Yes \\
\hline
\end{tabular}




\subsubsection{Calculation of the SQI}

After the MDS was determined, the soil quality was evaluated through three steps. First, the weight of the MDS indicator is calculated by the communality derived from the PCA (Table 6). The results show that $\mathrm{Na}$ and $\mathrm{AN}$ are more important than $\mathrm{pH}, \mathrm{OM}$ and $\mathrm{SK}$ in the soil quality evaluation because they have a higher weight. Furthermore, according to the grading standards of the second soil investigation in China and the relevant literature [31], the upper and lower thresholds of soil MDS evaluation indicators are determined. According to the impact of indicators on soil quality, the standard linear conversion function with the lower limit type described in Formula (2) was used for the standardized scoring of AN, OM and SK, whereas the opposite, Na were scored using the standard linear conversion function described in Formula (4). In general, $\mathrm{pH}$ was scored using the one described in Formula (3), however, the soil in the study area was slightly alkaline with a $\mathrm{pH}$ greater than 7 , so we scored it use Formula (4). Finally, the SQI is calculated by Formula (5).

Table 6. Standard scoring functions, communality and weight of soil quality indicators of the minimum data set (MDS).

\begin{tabular}{cccc}
\hline Indicator & SSF & Value & Weight \\
\hline $\mathrm{Na}$ & SSF3 & 0.881 & 0.241 \\
$\mathrm{pH}$ & SSF3 & 0.690 & 0.189 \\
$\mathrm{OM}$ & SSF1 & 0.623 & 0.170 \\
$\mathrm{AN}$ & SSF1 & 0.772 & 0.211 \\
SK & SSF1 & 0.691 & 0.189 \\
\hline
\end{tabular}

\subsection{Soil Quality Assessment in the Kenli District}

\subsubsection{The SQIs of Different Land Use Types}

The SQI of the 127 sampling points ranged from 0.237 to 0.836 , with an average value of 0.523 , a coefficient of variation of $26.0 \%$, and a moderate intensity variation. We used the soil quality classification standard in Wu's paper [31] for the Yellow River delta to classify the soil quality grade of the study area. According to the SQI $>0.7,0.6-0.7,0.5-0.6,0.4$ to 0.5 and $\leq 0.3$, the soil quality can be divided into levels I to VI, and I is the best level in terms of soil quality. The SQI of all sampling points was graded, and the results (Table 7) demonstrated that the proportion of grade IV soil was the highest, followed by grade III soil. The total proportion of these two grades was $52.7 \%$, whereas the proportion of grade VI soil was the lowest at only $3.9 \%$. The grade I point number was 2.6 -fold that of grade IV.

Table 7. The soil quality comprehensive index (SQI) value and quantitative proportion of different land use types in each soil quality grade.

\begin{tabular}{|c|c|c|c|c|c|c|c|c|c|c|c|c|c|c|c|}
\hline Land Use & Points & Means & $\mathrm{CV}$ & \multicolumn{2}{|c|}{ I $(>0.7)$} & \multicolumn{2}{|c|}{ II (0.6-0.7) } & \multicolumn{2}{|c|}{ III (0.5-0.6) } & \multicolumn{2}{|c|}{ IV (0.4-0.5) } & \multicolumn{2}{|c|}{$\mathrm{V}(0.3-0.4)$} & \multicolumn{2}{|c|}{ VI $(<0.3)$} \\
\hline Total & 127 & $0.52 \pm 0.14$ & 0.26 & 13 & $10.2 \%$ & 25 & $19.7 \%$ & 30 & $23.6 \%$ & 37 & $29.1 \%$ & 17 & $13.4 \%$ & 5 & $3.9 \%$ \\
\hline Cornfield & 7 & $0.60 \pm 0.2^{a}$ & 0.33 & 3 & $42.9 \%$ & 1 & $14.3 \%$ & 0 & $0.0 \%$ & 2 & $28.6 \%$ & 0 & $0.0 \%$ & 1 & $14.3 \%$ \\
\hline Cotton & 67 & $0.55 \pm 0.14^{\mathrm{a}}$ & 0.26 & 9 & $13.4 \%$ & 18 & $26.9 \%$ & 17 & $25.4 \%$ & 12 & $17.9 \%$ & 9 & $13.4 \%$ & 2 & $3.0 \%$ \\
\hline Forest & 14 & $0.48 \pm 0.07^{a b}$ & 0.15 & 0 & $0.0 \%$ & 1 & $7.1 \%$ & 4 & $28.6 \%$ & 8 & $57.1 \%$ & 1 & $7.1 \%$ & 0 & $0.0 \%$ \\
\hline Reed & 7 & $0.45 \pm 0.14^{\mathrm{ab}}$ & 0.31 & 0 & $0.0 \%$ & 1 & $14.3 \%$ & 1 & $14.3 \%$ & 2 & $28.6 \%$ & 2 & $28.6 \%$ & 1 & $14.3 \%$ \\
\hline Nudation & 6 & $0.36 \pm 0.07^{b}$ & 0.20 & 0 & $0.0 \%$ & 0 & $0.0 \%$ & 0 & $0.0 \%$ & 2 & $33.3 \%$ & 3 & $50.0 \%$ & 1 & $16.7 \%$ \\
\hline
\end{tabular}

Notes: Means followed by the same letters in the rows are not different at $p<0.05$ according to Tukey's test.

As evident in Figure 4A, the mean SQI of agricultural land (cotton and corn) was significantly increased compared with that of nudation, and the mean SQI of natural land type (grassland, forest, and reed) was lower than that of agricultural land and higher than that of nudation, without significant differences. The spatial variability in the SQI of farmland type is significantly increased compared with that of the natural land type and bare land type under the influence of cultivation years and cultivation modes. Due to its good adaptability to the environment [47], reeds have a wide spatial 
distribution and a large variation coefficient in the SQI. This feature is also noted in the distribution of soil quality grade. The soil quality of the cotton sampling points span across all the soil quality grades. Corn simultaneously also has grade I soil and grade VI soil, as well as various soil quality grades across a large span. The soil quality grade of the natural type is mainly grade IV, and the soil quality of nudation is worse than grade IV (mainly grade V).
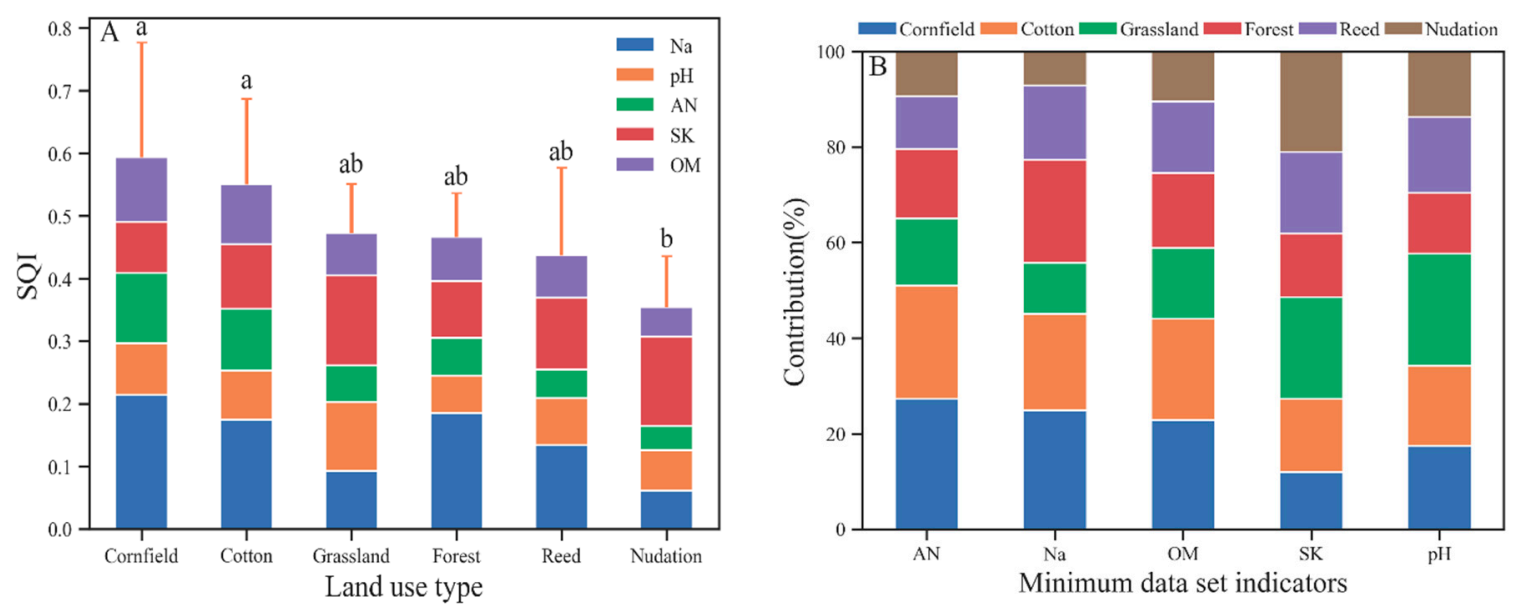

Figure 4. The SQI value of different land use types (A) and different townships with the individual contributions of each MDS indicator (B). Error bars denote the standard deviation of the overall indicator value. In B, OM, AN, and SK are not significantly different, the Na contribution of cornfield is significantly greater than that of nudation, and the $\mathrm{pH}$ contribution of grassland is significantly greater than that of forest.

According to the indicator contribution value and contribution rate of each land type's SQI (Figure 4B), in agricultural systems, the $\mathrm{pH}$ is high, $\mathrm{SK}$ is low, and the main limiting factors of farmland soil quality are SK and $\mathrm{pH}$. Natural type and nudation generally have lower AN and OM values, which are the main factors limiting soil quality. In addition, high $\mathrm{Na}$ was also an important factor limiting the soil quality of grassland and $\mathrm{pH}$ of forest. Compared with natural vegetation types and agricultural systems, $\mathrm{Na}$, which characterizes soil salinity, contributes minimally to SQI on bare land. The contribution rate of grassland $\mathrm{pH}$ to the soil SQI is significantly increased compared with that of other types.

\subsubsection{Spatial Distribution Characteristics of Soil Quality}

In Figure 5A, differences in the soil quality SQIs are noted between different towns in the Kenli District. Among them, the value for Huanghekou town is significantly greater than that for Yong'an, Dongji and Shengtuo. The value for Kenli Street is less than (not significantly) that for Huanghekou town but greater than (not significantly) that for the other three towns. No obvious spatial pattern is noted.

There are differences in the contribution of the MDS indicator to the SQI in each town (Figure 5B), reflecting the differences in soil ecology and soil management in different towns: Yong'an town is close to the coast and far from the Yellow River, and the amount of soil salt is very high. Kenli Street pH is high, which is the main limit on soil quality. No significant difference in the contribution of soil AN to soil quality was noted among the townships, but the value of the two towns in the west was lower than that on Kenli Street and the two towns in the east. The SK of Shengtuo town is significantly lower than that of the other townships, so this area should pay attention to the addition of potash fertilizer in its land use. Supplemented by the high OM in the alluvial sediment from the Yellow River, the contribution of OM to soil quality in Huanghekou town was the largest among all the townships and significantly greater than that in Dongji town and Yong'an town. 

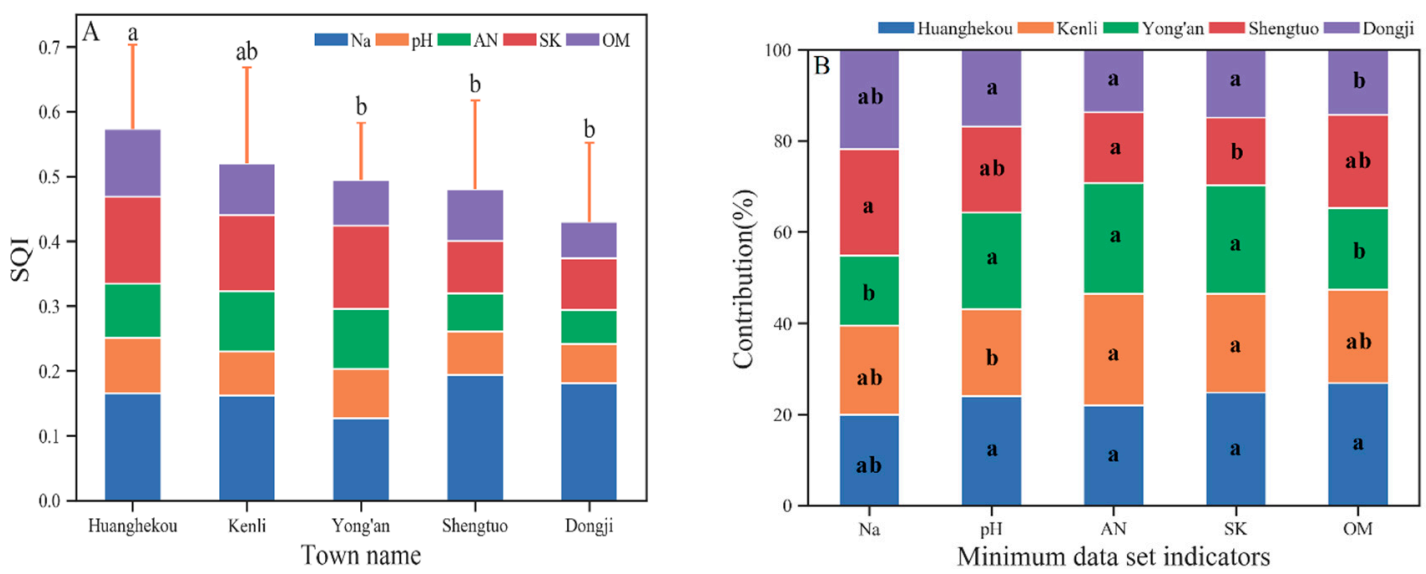

Figure 5. The SQI value of different townships with the individual contributions of each MDS indicator. Different lowercase letters represent values that are significantly different $(p \leq 0.05)$ between different productivity levels. Where (A) is the SQI value of different townships, and (B) is the individual contributions of each MDS indicator.

Then, we performed a geostatistical analysis of the SQI of the study area. The results of the spatial autocorrelation analysis show that Moran's I index $=0.13$, z-score $=1.65$, and the probability of randomly generating this clustering pattern is less than $10 \%$, which means that the SQI is spatially autocorrelated. Among all the models, the linear model can best explain the spatial variability in the SQI $\left(R^{2}=0.525\right.$, RSS $\left.=1.90 \times 10^{-5}\right)$; the nugget effect was 0.016 , and the base station value was 0.020 (Figure 6).

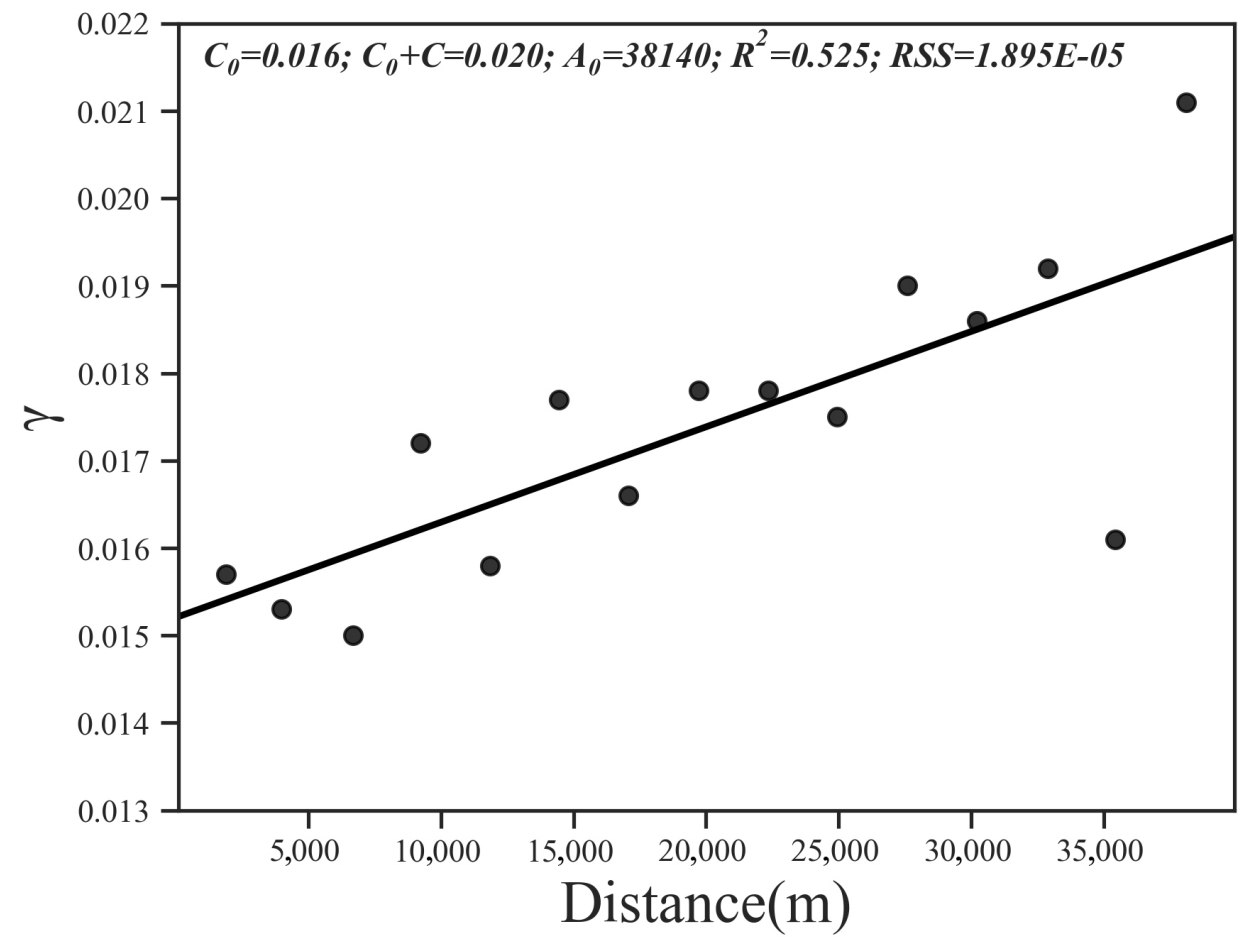

Figure 6. Omni-directional variograms calculated for SQI distribution.

By comparing 16 interpolation methods, IMTQ was identified the best method for spatial interpolation of the SQI (RMSE $=0.127)$, and the worst interpolation method was TPS (RMSE $=0.166)$. 
Figure 7 presents the IMTQ interpolation diagram of the spatial distribution of the SQI grade in the study area.

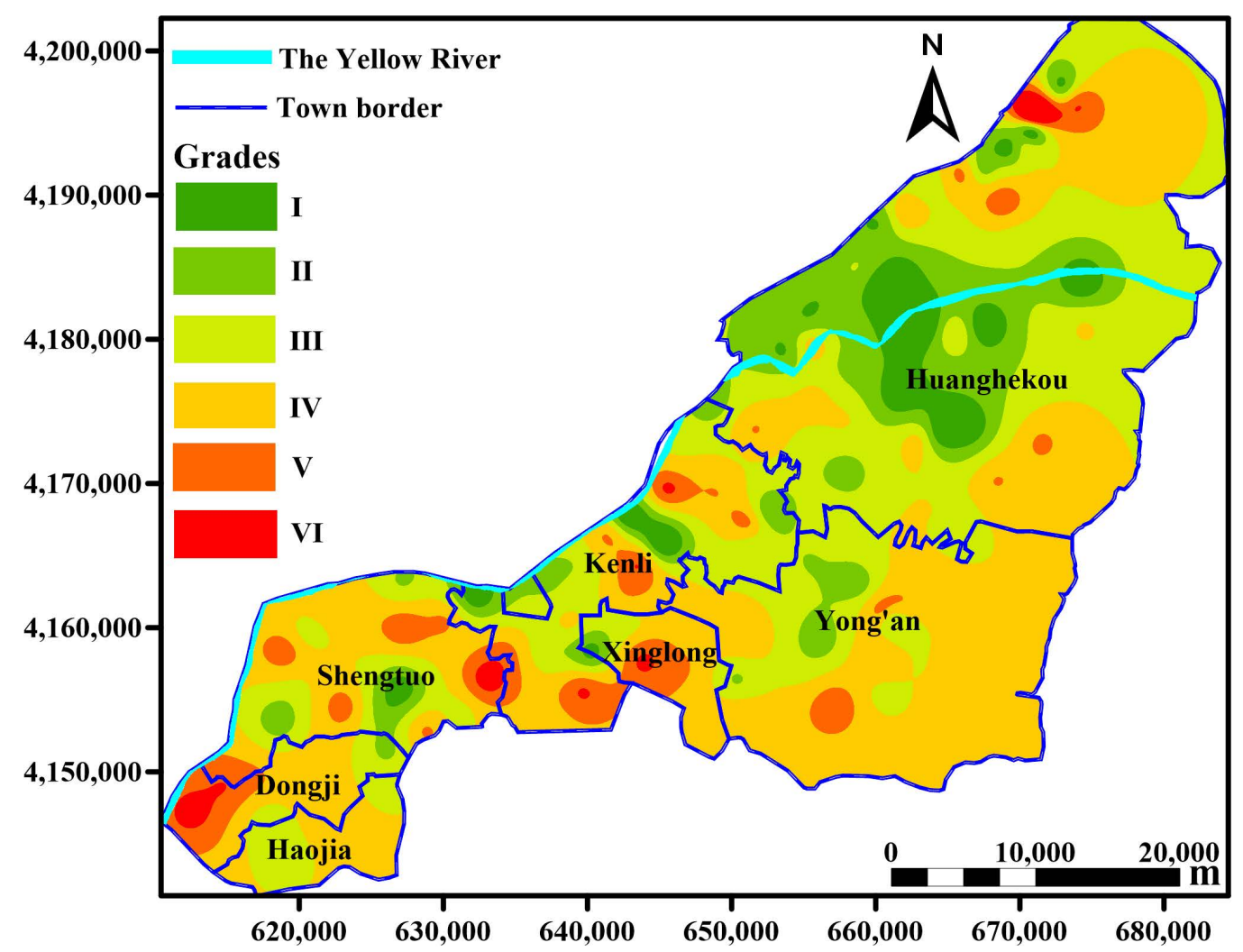

Figure 7. Spatial distribution of soil quality in the Kenli District in 2013. The grades in the figure refer to the grade classifications of soil quality. According to the SQI $>0.7,0.6-0.7,0.5-0.6,0.4$ to 0.5 and $\leq 0.3$, the soil quality can be divided into levels I to VI, and I is the best level in terms of soil quality. The interpolation graph is drawn by Golden Software Surfer 15 and color levels are assigned according to classification criteria.

Figure 7 demonstrates that the spatial distribution of soil quality has a strong regularity. Generally, the closer the study area is to the Yellow River, the better the soil quality is. Grade I soil is mainly concentrated in the vicinity of the Yellow River, especially in Huanghekou town. The distribution of grade VI soil is relatively scattered. Due to the high degree of urbanization around Kenli town, the soil quality is relatively poor. Overall, the soil in the Kenli District is poor in the central and western regions, whereas the eastern part has the best soil quality. According to the statistical analysis, the proportion of soil quality grades I-VI in the study area was $4.5 \%, 13.2 \%, 33.0 \%, 42.2 \%, 6.1 \%$ and $1.0 \%$, respectively. Grade III and grade IV account for the largest proportion, $75.2 \%$ of the total area, which is $22.5 \%$ greater than the statistical result of the sampling points. Grade I soil accounts for 4.5 times more area than grade VI soil, which is greater than the statistical result of the sampling points.

\subsection{Analysis of External Environmental Influencing Factors of SQI}

The ocean, Yellow River, microtopography and vegetation change play important roles in land generation, soil morphology, soil nutrients and salinity redistribution. In this study, the SQI was used as the dependent variable, and NDVI, Dr, Ds and Elev were used as independent variables for the linear regression analysis (Figure 8). 

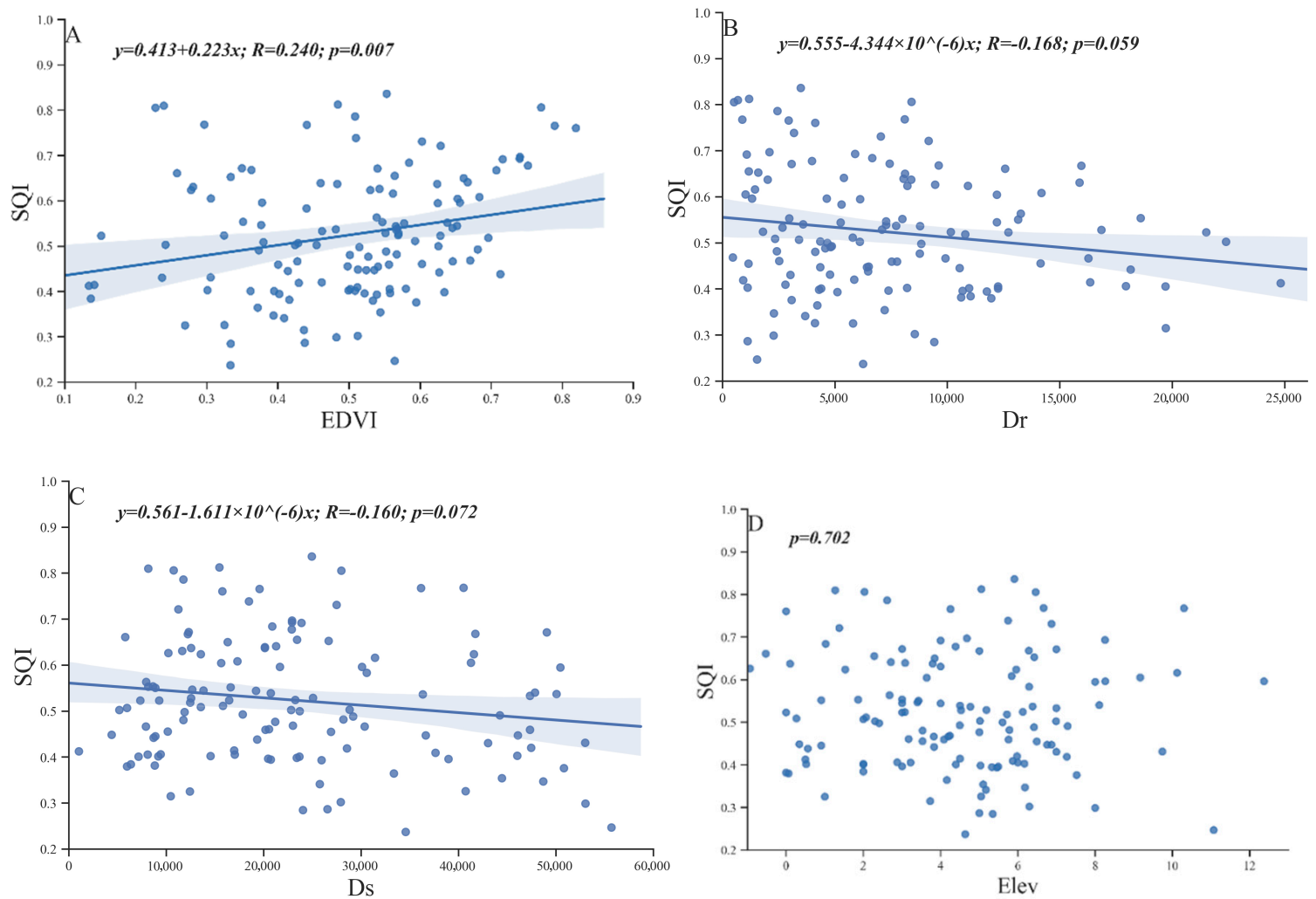

Figure 8. Correlations between the SQI and NDVI (A), Dr (B), Ds (C), and Elev (D) of 127 sampling points in the Kenli District.

The correlation coefficients between the four selected external environmental factors and SQI were relatively small. However, SQI and NDVI exhibited a very significant positive correlation (Figure 8A), and SQI was somewhat significantly $(0.05<p<0.1)$ negatively correlated with Dr and Ds (Figure $8 \mathrm{~B}, \mathrm{C})$. However, no correlation was noted between Elev and SQI (Figure 8D). Although the elevation of the study area fluctuated, the overall slope was approximately $1 / 10,000$, which was not sufficient to significantly affect the soil quality.

\section{Discussion}

\subsection{Scientific Evaluation and Explanation of the MDS}

The MDS method is widely accepted in the literature because it is carefully selected from a wide range of soil indicators $[27,48]$. In this paper, the MDS included $\mathrm{Na}, \mathrm{pH}, \mathrm{AN}, \mathrm{OM}$ and SK, which were screened by combining external environmental factors and the PCA method. Indicators used in the soil quality assessment should be site-specific and plant-specific [49]. The MDS indicators obtained in this paper fully considered the comprehensive soil chemical indicator and its effect on crop ecological plant growth in the Kenli District of the Yellow River delta. Some of these indicators (pH, AN, OM, and K) have also been widely used in many studies [4,28,29,31]. Wu et al. selected the minimum data set including TN, pH, AK and SOM to evaluate the soil quality of the Yellow River delta using the principal component analysis method assisted by environmental factors [31]. Zhang et al. used PCA to select AN, SOM, MBN(Microbial biomass carbon)/TC, and available zinc from 26 soil indicators as the minimum data set to evaluate the soil quality of the wheat-maize cropping system in the region of the dryland double cropping, China [4].

Nitrogen is one of the most important soil nutrients in farmlands and is a limiting nutrient in most ecosystems [50], especially effective nitrogen [51]. Soil OM is an important component of many soil biophysical properties [52], and plays a key role in improving soil fertility and ecosystem 
productivity [53-55]. Potassium is one of three essential nutrients for plant growth [56], and plays an important role in plant growth and metabolism. In addition, potassium can alleviate stress in plants under drought and salinization conditions [57]. Therefore, soil available potassium should be used as an important indicator of comprehensive SQI evaluation. Soil pH is an important indicator of soil alkalization.

$\mathrm{Na}$ is rarely selected as an MDS indicator in soil quality evaluations. However, in this paper, $\mathrm{Na}$ was selected as the characterization indicator of soil salinity in the Yellow River delta rather than EC because the former could reflect the influence of the external environmental factors on soil quality better than the latter (Table 4). Soil salinity results in growth inhibition, developmental changes, metabolic adaptations, and ion sequestration or exclusion. Both osmotic and toxic effects of sodium ions are involved [58]. These two processes were thought to be temporally and spatially separated, with sodium ions in the soil rapidly reducing water availability and a slow accumulation of sodium in the shoot inhibiting photosynthesis [59].

The assessment result and indicator screening were reasonable, as the spatial distribution of soil quality was similar to the actual conditions that we surveyed in the field. However, there was a flaw in this study. Because of the restrictions of experimental conditions, we could not get and analyze the characteristics of biological and physical indicators and their roles played in soil quality, and this was what we would solve in later researches.

\subsection{Rationality of the Soil Quality Evaluation in the Study Area}

According to Wu et al. [31], garden plots had the highest mean soil quality (value is 0.61 ) and the land use type with the second highest soil quality was farmland with a mean value of 0.58 , and farmland primarily had grade III soils. In our results, although corn fields have the best soil quality among all land types, the average SQI is just 0.60 (Table 7) and is classified as grade III, which are consistent with Wu's. In a similar study, Zhang et al. applied the same methodology for evaluating the SQI of the Yellow River delta wetland, they reported an SQI less than 0.53 and soil salt content had the highest SQI contribution ratio (34.1\%) among the indicators [29], which is exactly similar to those found in our study. Soil salt content was the limiting factor of soil quality due to its high contribution ratio to the SQI value (Figures 4A and 5A), indicating that the reclamation area in the Yellow River delta has a high salinity and a relatively poor soil quality. Under the conditions of artificial fertilization and soil mechanical improvement in saline land, the soil quality of agricultural land (cotton and corn) was greater than that of the natural land type (grassland, forest, and reed), and the soil quality of the natural land type was greater than that of nudation. Meng et al.'s research in east coastal region of China has come to the same conclusion, changes in different land use types due to plants and application of fertilizers were characterized by promoted soil quality [60]. And Gong et al.'s research for the saline oasis soil of the Keriya River Basin also reached a conclusion that concentrations of soil nutrients increased and land improvement occurred after land use shifts from natural land uses to cultivation [61].

Over the past few decades, increasing anthropogenic activities, such as urbanized agricultural activities and oil exploration, have led to rapid changes in land use and ecosystem fragmentation in the Yellow River delta. Since the 1980s when China implemented the household contract responsibility system, the area of arable land operated by individual farmers has been very small [62]. The spatial variability in soil nutrients is much greater than that in large-scale agriculture in developed countries [62]. These are the important factors that cause differences in the SQIs between different towns and the soil at all grades dispersed throughout the Kenli District. Nevertheless, due to the fresh water irrigation of the Yellow River and the rich nutrition of the new land near the coastal zone [63,64], the high quality soil was mainly distributed in areas close to the Yellow River and the coastline. The analysis of the influencing factors also showed that the Yellow River and coastal zone could promote the soil quality. Moreover, Wu's results showed that grade I was distributed only near the crossing of the Yellow River and the Diao River, which also supported our results [31]. However, the spatial variation 
and irregularity of the soil quality in this paper are significantly greater than those in Wu's study because the sampling density in this paper is higher, and the intertidal zones without sample points are eliminated in the interpolation process, the interpolation analysis may be more elaborate.

\subsection{Recommendations for Soil Management in the Yellow River Delta}

In the process of transformation of original natural land use to farmland, land degradation usually occurs $[65,66]$. Nevertheless, this conversion of natural vegetation to farmland does not always lead to land degradation $[67,68]$. Agricultural planting and natural vegetation growth could significantly reduce the soil salinity and improve the soil quality of saline-alkali soils [60,61], and a large number of studies have demonstrated that vegetation and soil quality can support each other [69]. Thus, in the process of developing and utilizing the coastal saline soil of the Yellow River delta, we can reasonably develop wastelands or protect natural vegetation systems to prevent degradation and nudation. Figure 4B shows that the soil $\mathrm{pH}$ can be reduced and the ecological environment can be improved by planting grass for high $\mathrm{pH}$ soils that are not suitable for development and utilization. In agricultural systems, $\mathrm{pH}$ is high, $\mathrm{SK}$ is low, and potash should be continuously added to improve soil quality and ensure crop yield. Figure 5B shows that the limiting factors of soil quality were different in each township due to the influences of the environment and the geographical location. In view of the differences and limiting factors of the soil quality of different land use types in different towns, we should propose land development and utilization strategies. For example, the $\mathrm{pH}$ of Kenli Street is high, and this area is highly urbanized, and the results above show that grassland can reduce the soil $\mathrm{pH}$, which is a limiting factor for the soil quality of forests. Therefore, in the process of soil greening in the Kenli Street area, we should consider planting lots of grass and planting trees carefully.

The formation and evolution of the land in the Yellow River delta is greatly influenced by the external environment [70]. The interaction between the Yellow River sediment and the Bohai Sea tide resulted in the formation of high-salt and high-nutrient land, and the plant growth stabilized the soil and improved the saline soil [34]. The results of this paper also proved that NDVI was directly proportional to soil quality. The Yellow River and Bohai Sea as the main material sources have the most obvious influence on the soil quality of the Yellow River delta. The soil near the Yellow River has high nutrient content, abundant fresh water resources and better soil quality. The soil in this area is good for agriculture. Close to the ocean, the soil is salty, but the tides bring nutrients. So, the area could be developed for salt-water farming or for salt-tolerant crops. These results are of great significance to soil development and utilization planning.

The study indicated that reasonable land use practices and scientific management patterns can improve and maintain the soil quality in the human-disturbed land-use systems in the Yellow River delta. However, other research has demonstrated that long-term cultivation can lead to soil degradation [71], which may explain the poor soil quality in the two western townships. Given the vulnerability of the Yellow River delta ecosystem, unreasonable land use can aggravate land degradation processes within fragile ecosystems. Therefore, sustainable land use and management are particularly important.

\section{Conclusions}

Five (Na, $\mathrm{pH}, \mathrm{OM}, \mathrm{AN}, \mathrm{SK})$ of the 10 soil indicators were selected as the MDS by PCA and external environmental factors, and the comprehensive quality index method was used to evaluate the soil quality in the Kenli District of the Yellow River delta. Based on the results of this study, the conclusions were as follows:

(1) The average SQI of Kenli is 0.52 , which is grade IV soil, and significant differences in the SQIs are noted among different land use types. The soil quality of agricultural land is greater than that of the natural land type as well as the bare land type. There is a certain law of the spatial distribution of soil SQI in the Kenli District, which mainly demonstrates that the closer the location is to the Yellow River, the better the soil quality will be. The soil quality of the eastern township is relatively greater than that of the western townships. 
(2) The analysis of the contribution of the MDS indicator to the SQI of each land type and township demonstrates that Na nitrogen and OM are the main indicators of limiting SQI in natural and bare land, and the main limiting factors of farmland soil quality are SK and $\mathrm{pH}$. The limiting indicators of SQI vary among towns. Therefore, in the process of land development and utilization, each township should formulate and implement different management and development strategies according to its own characteristics and land types.

(3) Within the study area, all NDVI, Ds, and Dr have different degrees of correlation with SQI. NDVI is positively correlated with SQI, and the two promote each other. Influenced by the freshwater and eutrophic fluvial marine sediments in the Yellow River, the closer the land is to the Yellow River and the coast, the better the soil quality is. In addition, no correlation was noted between elevation and soil quality in the study area.

Compared with similar studies in the Yellow River delta [29,31], this study describes in detail the spatial distribution of the soil quality of different grades in the county area, as well as the main limiting indicators of soil quality in towns and villages of different land types, and suggestions on the management and utilization of different land types in the township units of this region are proposed.

Author Contributions: Conceptualization, M.J., L.X. and X.C.; methodology, M.J. and H.Z.; software, H.F.; validation, L.X. and X.C.; formal analysis, M.J.; investigation, M.J. and X.C.; resources L.X. and X.C.; data curation, M.J. and H.Z.; writing — original draft preparation, M.J.; writing—review and editing, L.X.; visualization, H.F. and M.J.; supervision, L.X. and X.C.; project administration, L.X. and X.C.; funding acquisition, L.X. All authors have read and agreed to the published version of the manuscript.

Funding: This research was funded by the National Key Research and Development Program of China (2018YFE0206400 and 2018YFC0407606), the National Natural Science Foundation of China (41971137 and 41771235), the Special Fund for Key R\&D Program of Shandong (2017CXGC0316), the STS Key Projects of the Chinese Academy of Sciences (KFJ-STS-QYZD-098), the Science and Technology Planning Project of Qinghai Province (2019-HZ-818), the Nanjing Institute of Geography \& Limnology (NIGLAS2019QD005) and the National Natural Science Foundation of China (U1806215).

Acknowledgments: We convey our sincere thanks to Kun Yan (Yantai Institute of Coastal Zone Research, CAS) and Yunpeng Sun (Institute of Soil Science, CAS). We also thank Congwen Wu for helping with the experiments.

Conflicts of Interest: The authors declare no conflict of interest.

\section{References}

1. Zhang, Y.; Luo, P.; Zhao, S.; Kang, S.; Wang, P.; Zhou, M.; Lyu, J. Control and remediation methods for eutrophic lakes in the past 30 years. Water Sci. Technol. 2020, 81, 1099-1113. [CrossRef] [PubMed]

2. Fernandes, J.C.; Gamero, C.A.; Lanca Rodrigues, J.G.; Miras-Avalos, J.M. Determination of the quality index of a Paleudult under sunflower culture and different management systems. Soil Tillage Res. 2011, 112, 167-174. [CrossRef]

3. Luo, P.; Sun, Y.; Wang, S.; Wang, S.; Lyu, J.; Zhou, M.; Nakagami, K.; Takara, K.; Nover, D. Historical assessment and future sustainability challenges of Egyptian water resources management. J. Clean. Prod. 2020, 263, 121154. [CrossRef]

4. Li, P.; Shi, K.; Wang, Y.; Kong, D.; Liu, T.; Jiao, J.; Liu, M.; Li, H.; Hu, F. Soil quality assessment of wheat-maize cropping system with different productivities in China: Establishing a minimum data set. Soil Tillage Res. 2019, 190, 31-40. [CrossRef]

5. McGrath, D.; Zhang, C. Spatial distribution of soil organic carbon concentrations in grassland of Ireland. Appl. Geochem. 2003, 18, 1629-1639. [CrossRef]

6. Bindraban, P.S.; Stoorvogel, J.J.; Jansen, D.M.; Vlaming, J.; Groot, J.J.R. Land quality indicators for sustainable land management: Proposed method for yield gap and soil nutrient balance. Agric. Ecosyst. Environ. 2000, 81, 103-112. [CrossRef]

7. Mu, D.; Luo, P.; Lyu, J.; Zhou, M.; Huo, A.; Duan, W.; Nover, D.; He, B.; Zhao, X. Impact of temporal rainfall patterns on flash floods in Hue City, Vietnam. J. Flood Risk Manag. 2020. [CrossRef]

8. Arslan, S. Assessment of groundwater and soil quality for agricultural purposes in Kopruoren basin, Kutahya, Turkey. J. Afr. Earth Sci. 2017, 131, 1-13. [CrossRef] 
9. Lin, Y.; Deng, H.; Du, K.; Li, J.; Lin, H.; Chen, C.; Fisher, L.; Wu, C.; Hong, T.; Zhang, G. Soil quality assessment in different climate zones of China's Wenchuan earthquake affected region. Soil Tillage Res. 2017, 165, 315-324. [CrossRef]

10. Cheng, J.; Ding, C.; Li, X.; Zhang, T.; Wang, X. Soil quality evaluation for navel orange production systems in central subtropical China. Soil Tillage Res. 2016, 155, 225-232. [CrossRef]

11. Firdous, S.; Begum, S.; Yasmin, A. Assessment of soil quality parameters using multivariate analysis in the rawal lake watershed. Environ. Monit. Assess. 2016, 188, 533. [CrossRef] [PubMed]

12. Zuber, S.M.; Behnke, G.D.; Nafziger, E.D.; Villamil, M.B. Multivariate assessment of soil quality indicators for crop rotation and tillage in Illinois. Soil Tillage Res. 2017, 174, 147-155. [CrossRef]

13. Memoli, V.; De Marco, A.; Esposito, F.; Panico, S.C.; Barile, R.; Maisto, G. Seasonality, altitude and human activities control soil quality in a national park surrounded by an urban area. Geoderma 2019, 337, 1-10. [CrossRef]

14. Nabiollahi, K.; Golmohamadi, F.; Taghizadeh-Mehrjardi, R.; Kerry, R.; Davari, M. Assessing the effects of slope gradient and land use change on soil quality degradation through digital mapping of soil quality indices and soil loss rate. Geoderma 2018, 318, 16-28. [CrossRef]

15. Biswas, S.; Hazra, G.C.; Purakayastha, T.J.; Saha, N.; Mitran, T.; Singha Roy, S.; Basak, N.; Mandal, B. Establishment of critical limits of indicators and indices of soil quality in rice-rice cropping systems under different soil orders. Geoderma 2017, 292, 34-48. [CrossRef]

16. Mukhopadhyay, S.; Masto, R.E.; Yadav, A.; George, J.; Ram, L.C.; Shukla, S.P. Soil quality index for evaluation of reclaimed coal mine spoil. Sci. Total Environ. 2016, 542, 540-550. [CrossRef] [PubMed]

17. Andrews, S.S.; Karlen, D.L.; Mitchell, J.P. A comparison of soil quality indexing methods for vegetable production systems in Northern California. Agric. Ecosyst. Environ. 2002, 90, 25-45. [CrossRef]

18. Nabiollahi, K.; Taghizadeh-Mehrjardi, R.; Eskandari, S. Assessing and monitoring the soil quality of forested and agricultural areas using soil-quality indices and digital soil-mapping in a semi-arid environment. Arch. Agron. Soil Sci. 2018, 64, 696-707. [CrossRef]

19. Xue, Y.-J.; Liu, S.-G.; Hu, Y.-M.; Yang, J.-F. Soil quality assessment using weighted fuzzy association rules. Pedosphere 2010, 20, 334-341. [CrossRef]

20. Larson, W.E.; Pierce, F.J. The dynamics of soil quality as a measure of sustainable management. Defin. Soil Qual. Sustain. Environ. 1994, 35, 37-51. [CrossRef]

21. Karlen, D.L.; Tomer, M.D.; Neppel, J.; Cambardella, C.A. A preliminary watershed scale soil quality assessment in north central Iowa, USA. Soil Tillage Res. 2008, 99, 291-299. [CrossRef]

22. Ditzler, C.A.; Tugel, A.J. Soil quality field tools: Experiences of USDA-NRCS soil quality institute. Agron. J. 2002, 94, 33-38. [CrossRef]

23. Andrews, S.S.; Flora, C.B.; Mitchell, J.P.; Karlen, D.L. Growers' perceptions and acceptance of soil quality indices. Geoderma 2003, 114, 187-213. [CrossRef]

24. Andrews, S.S.; Karlen, D.L.; Cambardella, C.A. The soil management assessment framework. Soil Sci. Soc. Am. J. 2004, 68, 1945-1962. [CrossRef]

25. Qi, Y.; Darilek, J.L.; Huang, B.; Zhao, Y.; Sun, W.; Gu, Z. Evaluating soil quality indices in an agricultural region of Jiangsu Province, China. Geoderma 2009, 149, 325-334. [CrossRef]

26. Lin, Y.; Ye, Y.; Wu, C.; Yang, J.; Hu, Y.; Shi, H. Comprehensive assessment of paddy soil quality under land consolidation: A novel perspective of microbiology. PEERJ 2019, 7. [CrossRef]

27. Rezaei, S.A.; Gilkes, R.J.; Andrews, S.S. A minimum data set for assessing soil quality in rangelands. Geoderma 2006, 136, 229-234. [CrossRef]

28. Yao, R.; Yang, J.; Gao, P.; Zhang, J.; Jin, W. Determining minimum data set for soil quality assessment of typical salt-affected farmland in the coastal reclamation area. Soil Tillage Res. 2013, 128, 137-148. [CrossRef]

29. Zhang, G.L.; Bai, J.H.; Xi, M.; Zhao, Q.Q.; Lu, Q.Q.; Jia, J. Soil quality assessment of coastal wetlands in the yellow river delta of China based on the minimum data set. Ecol. Indic. 2016, 66, 458-466. [CrossRef]

30. Chen, Y.-D.; Wang, H.-Y.; Zhou, J.-M.; Xing, L.; Zhu, B.-S.; Zhao, Y.-C.; Chen, X.-Q. Minimum data set for assessing soil quality in farmland of Northeast China. Pedosphere 2013, 23, 564-576. [CrossRef]

31. Wu, C.S.; Liu, G.H.; Huang, C.; Liu, Q.S. Soil quality assessment in yellow river delta: Establishing a minimum data set and fuzzy logic model. Geoderma 2019, 334, 82-89. [CrossRef]

32. Fan, X.; Pedroli, B.; Liu, G.; Liu, Q.; Liu, H.; Shu, L. Soil salinity development in the yellow river delta in relation to groundwater dynamics. Land Degrad. Dev. 2012, 23, 175-189. [CrossRef] 
33. Han, G.; Sun, B.; Chu, X.; Xing, Q.; Song, W.; Xia, J. Precipitation events reduce soil respiration in a coastal wetland based on four-year continuous field measurements. Agric. For. Meteorol. 2018, 256-257, 292-303. [CrossRef]

34. Cui, B.; Yang, Q.; Yang, Z.; Zhang, K. Evaluating the ecological performance of wetland restoration in the Yellow River Delta, China. Ecol. Eng. 2009, 35, 1090-1103. [CrossRef]

35. Guo, L.; Sun, Z.; Ouyang, Z.; Han, D.; Li, F. A comparison of soil quality evaluation methods for Fluvisol along the lower Yellow River. CATENA 2017, 152, 135-143. [CrossRef]

36. Luan, Z.; Deng, W. Tidal and fluvial influence on shallow groundwater fluctuation in coastal wetlands in Yellow River Delta, China. Clean Soil Air Water 2013, 41, 534-538. [CrossRef]

37. Yang, M.; Liu, S.; Yang, Z.; Sun, T.; DeGloria, S.D.; Holt, K. Effect on soil properties of conversion of Yellow River Delta ecosystems. Wetlands 2009, 29, 1014. [CrossRef]

38. Lu, R. Analytical Methods of Soil Agrochemistry; China Agricultural Science and Technology Publishing House: Beijing, China, 1999; pp. 18-99. [CrossRef]

39. Fathizad, H.; Ardakani, M.A.H.; Heung, B.; Sodaiezadeh, H.; Rahmani, A.; Fathabadi, A.; Scholten, T.; Taghizadeh-Mehrjardi, R. Spatio-temporal dynamic of soil quality in the central Iranian desert modeled with machine learning and digital soil assessment techniques. Ecol. Indic. 2020, 118, 106736. [CrossRef]

40. Wu, C.; Liu, Q.; Ma, G.; Liu, G.; Yu, F.; Huang, C.; Zhao, Z.; Liang, L. A study of the spatial difference of the soil quality of the mun river basin during the rainy season. Sustainability 2019, 11, 3423. [CrossRef]

41. Aziz, S.; Ngui, R.; Lim, Y.A.; Sholehah, I.; Nur Farhana, J.; Azizan, A.S.; Wan Yusoff, W.S. Spatial pattern of 2009 dengue distribution in Kuala Lumpur using GIS application. Trop. Biomed. 2012, 29, 113-120. [PubMed]

42. Pulido, M.; Schnabel, S.; Contador, J.F.L.; Lozano-Parra, J.; Gomez-Gutierrez, A. Selecting indicators for assessing soil quality and degradation in rangelands of Extremadura (SW Spain). Ecol. Indic. 2017, 74, 49-61. [CrossRef]

43. Nabiollahi, K.; Taghizadeh-Mehrjardi, R.; Kerry, R.; Moradian, S. Assessment of soil quality indices for salt-affected agricultural land in Kurdistan Province, Iran. Ecol. Indic. 2017, 83, 482-494. [CrossRef]

44. Li, P.; Zhang, T.; Wang, X.; Yu, D. Development of biological soil quality indicator system for subtropical China. Soil Tillage Res. 2013, 126, 112-118. [CrossRef]

45. Yang, C.S.; Kao, S.-P.; Lee, F.B.; Hung, P.S. Twelve different interpolation methods: A case study of Surfer 8.0. In Proceedings of the XXth ISPRS Congress, Istanbul, Turkey, 12-23 July 2004; pp. 778-785.

46. Zhang, Y.; Yang, J.; Yao, R.; Wang, X.; Xie, W. Short-term effects of biochar and gypsum on soil hydraulic properties and sodicity in a saline-alkali soil. Pedosphere 2020, 30, 694-702. [CrossRef]

47. Ruiz, M.; Velasco, J. Nutrient bioaccumulation in phragmites australis: Management tool for reduction of pollution in the mar menor. Wate Air Soil Pollut. 2009, 205, 173. [CrossRef]

48. Govaerts, B.; Sayre, K.D.; Deckers, J. A minimum data set for soil quality assessment of wheat and maize cropping in the highlands of Mexico. Soil Tillage Res. 2006, 87, 163-174. [CrossRef]

49. K.L, S.; Kumar, U.; Gajbhiye, P.; Karlapudi, S.; Korwar, G.; Hima, V.; Varadharajan, R.; Ramachandran, K.; Yadav, S. Evaluation of long-term soil management practices using key indicators and soil quality indices in a semi-arid tropical Alfisol. Aust. J. Soil Res. 2008, 46, 368-377. [CrossRef]

50. Fenn, M.E.; Poth, M.A.; Aber, J.D.; Baron, J.S.; Bormann, B.T.; Johnson, D.W.; Lemly, A.D.; McNulty, S.G.; Ryan, D.F.; Stottlemyer, R. Nitrogen excess in North American ecosystems: Predisposing factors, ecosystem responses, and management strategies. Ecol. Appl. 1998, 8, 706-733. [CrossRef]

51. Weil, R.; Brady, N. The Nature and Properties of Soils, 15th ed.; Pearson: Upper Saddle River, NJ, USA, 2017.

52. Gregorich, E.G.; Monreal, C.M.; Carter, M.R.; Angers, D.A.; Ellert, B.H. Towards a minimum data set to assess soil organic matter quality in agricultural soils. Can. J. Soil Sci. 1994, 74, 367-385. [CrossRef]

53. Dawe, D.; Dobermann, A.; Ladha, J.K.; Yadav, R.L.; Bao, L.; Gupta, R.K.; Lal, P.; Panaullah, G.; Sariam, O.; Singh, Y.; et al. Do organic amendments improve yield trends and profitability in intensive rice systems? Field Crops Res. 2003, 83, 191-213. [CrossRef]

54. Janzen, H.H. The soil carbon dilemma: Shall we hoard it or use it? Soil Biol. Biochem. 2006, 38, 419-424. [CrossRef]

55. Manlay, R.J.; Feller, C.; Swift, M.J. Historical evolution of soil organic matter concepts and their relationships with the fertility and sustainability of cropping systems. Agric. Ecosyst. Environ. 2007, 119, 217-233. [CrossRef]

56. Cakmak, I. Potassium for better crop production and quality. Plant Soil 2010, 335, 1-2. [CrossRef] 
57. Cakmak, I. The role of potassium in alleviating detrimental effects of abiotic stresses in plants. J. Plant Nutr. Soil Sci. 2005, 168, 521-530. [CrossRef]

58. Munns, R.; Tester, M. Mechanisms of salinity tolerance. Annu. Rev. Plant Biol. 2008, 59, 651-681. [CrossRef]

59. Van Zelm, E.; Zhang, Y.; Testerink, C. Salt tolerance mechanisms of plants. Annu. Rev. Plant Biol. 2020, 71, 403-433. [CrossRef]

60. Meng, Q.; Yang, J.; Yao, R.; Liu, G. Soil quality in east coastal region of China as related to different land use types. J. Soils Sediments 2013, 13, 664-676. [CrossRef]

61. Gong, L.; Ran, Q.; He, G.; Tiyip, T. A soil quality assessment under different land use types in Keriya river basin, Southern Xinjiang, China. Soil Tillage Res. 2015, 146, 223-229. [CrossRef]

62. Zhang, Q.; Yang, Z.; Li, Y.; Chen, D.; Zhang, J.; Chen, M. Spatial variability of soil nutrients and GIS-based nutrient management in Yongji County, China. Int. J. Geogr. Inf. Sci. 2010, 24, 965-981. [CrossRef]

63. Ding, Y.; Ye, S.; Zhao, Q. Nutrients and carbon sequestration in the newly created wetlands of yellow river delta. Geol. Rev. (Chin.) 2012, 58, 183-189. [CrossRef]

64. Qixiang, S.U.N.; Zhang, J.; Franz, M. Evaluation of soil chemical properties and enzymes activityunder different land use systems. J. Soil Water Conserv. (Chin.) 2006, 20, 98-101. [CrossRef]

65. Jaiyeoba, I.A. Changes in soil properties due to continuous cultivation in Nigerian semiarid Savannah. Soil Tillage Res. 2003, 70, 91-98. [CrossRef]

66. Caravaca, F.; Masciandaro, G.; Ceccanti, B. Land use in relation to soil chemical and biochemical properties in a semiarid Mediterranean environment. Soil Tillage Res. 2002, 68, 23-30. [CrossRef]

67. Thuille, A.; Buchmann, N.; Schulze, E.-D. Carbon stocks and soil respiration rates during deforestation, grassland use and subsequent Norway spruce afforestation in the Southern Alps, Italy. Tree Physiol. 2000, 20, 849-857. [CrossRef] [PubMed]

68. Luo, G.; Chen, X.; Xu, W. Soil properties related to land-use systems in oases of Sangong river watershed, Xinjiang. J. Geogr. Sci. 2008, 18, 483-498. [CrossRef]

69. Zhang, Y.W.; Shangguan, Z.-P. The coupling interaction of soil water and organic carbon storage in the long vegetation restoration on the Loess Plateau. Ecol. Eng. 2016, 91, 574-581. [CrossRef]

70. Xu, X.; Guo, H.; Chen, X.; Lin, H.; Du, Q. A multi-scale study on land use and land cover quality change: The case of the Yellow River Delta in China. GeoJournal 2002, 56, 177-183. [CrossRef]

71. Gui, D.; Lei, J.; Mu, G.; Zeng, F. Effects of different management intensities on soil quality of farmland during oasis development in southern Tarim Basin, Xinjiang, China. Int. J. Sustain. Dev. World Ecol. 2009, 16, 295-301. [CrossRef]

Publisher's Note: MDPI stays neutral with regard to jurisdictional claims in published maps and institutional affiliations.

(C) 2020 by the authors. Licensee MDPI, Basel, Switzerland. This article is an open access article distributed under the terms and conditions of the Creative Commons Attribution (CC BY) license (http://creativecommons.org/licenses/by/4.0/). 